\title{
Review Article \\ TNF Blocking Therapies and Immunomonitoring in Patients with Inflammatory Bowel Disease
}

\author{
Romain Altwegg $^{1}$ and Thierry Vincent ${ }^{2}$ \\ ${ }^{1}$ Département d'Hépatogastroentérologie, Hôpital Saint-Eloi, Centre Hospitalier Universitaire de Montpellier, \\ 80 Avenue Augustin Fliche, 34295 Montpellier, France \\ ${ }^{2}$ Département d'Immunologie, Hôpital Saint-Eloi, Centre Hospitalier Universitaire de Montpellier, 80 Avenue Augustin Fliche, \\ 34295 Montpellier Cedex 5, France
}

Correspondence should be addressed to Thierry Vincent; t-vincent@chu-montpellier.fr

Received 28 June 2013; Revised 15 January 2014; Accepted 17 February 2014; Published 18 March 2014

Academic Editor: Sophie Desplat-Jégo

Copyright (C) 2014 R. Altwegg and T. Vincent. This is an open access article distributed under the Creative Commons Attribution License, which permits unrestricted use, distribution, and reproduction in any medium, provided the original work is properly cited.

\begin{abstract}
Since their appearance in the armamentarium for inflammatory bowel disease (IBD) more than a decade ago, antitumor necrosis factor (TNF) inhibitors have demonstrated beneficial activity in induction and maintenance of clinical remission, mucosal healing, improvement in quality of life, and reduction in surgeries and hospitalizations. However, more than one-third of patients present primary resistance, and another one-third become resistant over time. One of the main factors associated with loss of response is the immunogenicity of anti-TNF biologics leading to the production of antidrug antibodies (ADAbs) accelerating their clearance. In this review we present the current state of the literature on the place of TNF and its blockage in the treatment of patients with IBD and discuss the usefulness of serum trough levels and ADAb monitoring in the optimization of anti-TNF therapies.
\end{abstract}

\section{Introduction}

Antitumor necrosis factor (TNF) biologics appeared over a decade ago in the armamentarium for inflammatory bowel disease (IBD). Originally evaluated in Crohn's disease (CD) and thereafter in ulcerative colitis (UC), their efficacy was demonstrated in both diseases and has deeply modified the management of patients with IBD [1]. Although they are potentially able to change the natural course of IBD and to decrease the need for surgery, absence or loss of response is frequent and only one-third of patients remain in clinical remission at 1 year [2]. Clinical response, steroid-free remission, and mucosal healing have been correlated with drug trough levels $[3,4]$. However, anti-TNF pharmacokinetic is characterized by a considerable interindividual variability and antidrug antibodies (ADAbs) have been identified as one of the major factors impacting their clearance [5]. Thus, serum trough levels and ADAb measurement have been proposed for the monitoring of anti-TNF drugs and algorithms were defined for the management of patients with IBD [6].

\section{Role of TNF in IBD Pathophysiology}

While the etiology of IBD is still unknown, it is thought to involve complex interactions between genetic disposition, environmental conditions, life style, and microbial and immune factors resulting in a deregulated and excessive immune response directed against components of the normal microflora. CD and UC have been associated with exaggerated $\mathrm{T}$ helper (Th) type 1 and Th2 responses, respectively. More recent studies demonstrated that tissue damages result from mucosal inflammation mainly mediated by proinflammatory Th1 and Th17 lymphocyte subpopulations and their respective proinflammatory effector cytokines. In the gut of CD patients, activated Thl and Th17 cells produce IFN $\gamma$ and IL17 (A and F), respectively, which stimulate macrophages and induce the production of other inflammatory cytokines such as IL- $1 \beta$ and TNF $\alpha$ that subsequently promote matrix metalloproteinases (MMPs) production by stroma cells and mucosal damage [7]. Thus, it is now widely accepted that TNF $\alpha$ plays a strategic role in IBD pathophysiology, at the cross talk of the different inflammatory pathways involved 
in gut mucosal inflammation [8]. Accordingly, most of the efficient biologic therapies developed so far in IBD aimed at neutralizing the proinflammatory activity of the TNF pathway. The effects of TNF $\alpha$ are known to be mediated by TNF receptor I (TNF-RI) or TNF-RII. Ligation of TNF$\mathrm{RI}$, which is expressed on a wide range of immune and nonimmune cells, results in NF- $\kappa \mathrm{B}$ activation, cytotoxicity, and induction of proinflammatory cytokines and chemokines as well as antiapoptotic peptides $[9,10]$. The effects on $\mathrm{T}$ lymphocytes are mainly mediated by interaction of TNF $\alpha$ with TNF-RII inducing a costimulatory signal to TCRmediated $\mathrm{T}$ cell activation, thereby increasing $\mathrm{T}$ cell proliferation, expression of $\mathrm{T}$ cell activation markers (CD25, human leukocyte antigen-DR, and TNF-RII), and secretion of inflammatory cytokines including IFN $\gamma$ and TNF $\alpha$ [11]. Accordingly, anti-TNF are able to inhibit $\mathrm{T}$ cell activation resulting in a decrease of proliferation and cytokine secretion (IFN- $\gamma$, IL-13, IL-17A, and TNF $\alpha$ ) of both CD4+ and CD8+ $\mathrm{T}$ cell populations derived from UC patients [12]. On the other hand, TNF $\alpha$ and TNF-RII are also able to activate and expand protective CD4(+)FoxP3(+) regulatory T cells (Tregs) and seem critical for the stabilization of their phenotype and function in the inflammatory environment of the lamina propria in a mouse model of colitis [13]. These contrasting effects of $\mathrm{TNF} \alpha$ on effector versus regulatory $\mathrm{T}$ cells may explain unexpected and disappointing results obtained with anti-TNF in some autoimmune diseases such as multiple sclerosis [14]. Altogether, these data underline the complexity of TNF $\alpha$ function via TNF-RI or TNF-RII on the course of intestinal inflammation, due to different susceptibility of epithelial cells and effector or regulatory immune cells. As an illustration, in dextran sulfate sodium- (DSS-) induced acute colitis in BALB/c mice, TNF-RI ablation led to exacerbation of the disease with increased inflammation and intestinal damage, while TNF-RII deficiency had opposite effects [15]. Nonetheless, studies in patients with IBD have extensively demonstrated the efficiency of anti-TNF therapies which directly inhibit activation of effector $\mathrm{T}$ cells and sensitize them to Treg-mediated inhibition with final restoration of immune homeostasis, resolution of inflammation, and mucosal healing. Further studies are now required to better understand the respective protective and deleterious effects mediated by $\mathrm{TNF} \alpha$ on immune and nonimmune cells through TNF-RI and TNF-RII in order to develop more specific inhibitors with potentially an increased efficacy and/or safety.

\section{Anti-TNF Therapies in Patients with IBD}

TNF $\alpha$ is the major target molecule of biologic treatments in CD and UC. Numerous randomized clinical trials and meta-analyses have demonstrated the efficacy of monoclonal antibodies against TNF $\alpha$ for both induction and maintenance of remission in both CD and UC [16-18]. Infliximab (IFX), a chimeric monoclonal antibody composed of human constant and murine variable regions, and adalimumab, a fully human monoclonal IgG1 anti-TNF antibody, demonstrated their efficacy for the control of disease activity and the induction of clinical remission and mucosal healing in luminal CD and UC both in children and adult patients [1, 19-25]. Several randomized clinical trials showed a better efficacy in inducing steroid-free clinical remission for a combination therapy with immunomodulators than anti-TNF monotherapy in CD and UC [26]. Moreover several studies established the use of infliximab and adalimumab in active fistulizing CD in adult patients [27, 28]. Certolizumab, a polyethylene-glycolated Fab' fragment of anti-TNF Ab, also produced significant clinical benefit and mucosal healing in adult patients with CD [29]. Recently, golimumab, a fully human monoclonal antibody to $\mathrm{TNF} \alpha$, was shown to induce and maintain clinical response in patients with active moderate-to-severe UC $[30,31]$.

However, although 60 to 80 percent of patients exhibit a good initial response to anti-TNF treatments (defined as a Crohn's Disease Activity Index (CDAI) decrease from baseline $>70$ points for CD and a decrease in the Mayo score of at least 3 points and at least 30 percent for UC), only onethird of patients are in clinical remission without steroids at one year (defined as a CDAI $<150$ for CD and a total Mayo score of 2 points or lower, with no individual subscore exceeding 1 point for UC) [18]. Consequently, 20 to 30 percent of patients require dose intensification or interval adjustment in order to maintain long-term clinical benefit and an average of 10 to 20 percent per year lose response [32-36].

\section{Drug Monitoring of Anti-TNF Biologics}

Despite the high effectiveness of anti-TNF in patients with IBD, more than one-third of patients present primary resistance, and another one-third become resistant over time [37]. Optimal clinical response required the maintenance of clinically effective drug concentrations, but the pharmacokinetic of anti-TNF is highly variable among patients and could be influenced by numerous factors including gender, body weight, associated treatments (immunosuppressants are known to increase anti-TNF trough levels), route of administration, serum albumin concentration, and systemic inflammation with a markedly decreased half-life in patients with severe disease [38-40]. However, the main factor impacting anti-TNF pharmacokinetic and efficacy over time is immunogenicity whereby antidrug antibodies (ADAbs) accelerate anti-TNF monoclonal Abs clearance and shorten their half-life [41, 42]. Although humanized (e.g., certolizumab) and fully human Abs (e.g., adalimumab and golimumab) are logically less immunogenic as compared with chimeric ones (e.g., IFX), they can all induce ADAbs targeting murine and/or variable domains of the monoclonal $\mathrm{Ab}$. Other factors may promote immunogenicity such as genotype in a minority of patients and drug agitation or freeze-thaw cycles that can induce immunogenic protein aggregates (for review [43]). Contrastingly, prescription of maintenance therapy with concomitant immunomodulators and achievement of suitable trough drug levels have been shown to reduce the risk of ADAbs [44].

Several studies assessed IFX trough levels after induction treatment or during maintenance therapy as predictors of 
sustained clinical response and showed a significant correlation between low IFX trough levels and decreased clinical response in $\mathrm{CD}$ and $\mathrm{UC}$ adult patients [3, 4, 34, 45-47] and in children with UC [48]. In a recent prospective study of IBD patients who have developed secondary failure to IFX, Paul et al. have shown that the only factor associated with mucosal healing after IFX optimization was a significant increase in IFX trough levels [49]. Antibodies to IFX (ATIs) were described in up to $60 \%$ when IFX was used on an ad hoc basis in practice and in 10 to $20 \%$ of patients in randomized controlled trials of maintenance therapy [43]. ATIs were associated with loss of clinical response, deterioration of endoscopic activity, infusion reactions, and low serum IFX concentrations [5, 41, 44, 46, 50-52]. However, some studies did not observe significant correlation between trough levels of IFX and CD activity or between positivity of ATIs and loss of clinical response or deterioration of endoscopic activity [3, 4, 53-55]. These discrepancies could be explained by different methods of measurements for ATIs and IFX concentrations, by the short follow-up time in some studies, and by the lack of consensual optimal levels of IFX for prediction of efficacy.

There are fewer data for adalimumab, but some studies also described a positive association between serum adalimumab concentration and clinical remission in CD [56-58]. Furthermore, while fully human, antiadalimumab antibodies were described in 2.6 to 17 percent of patients treated for $\mathrm{CD}$ or rheumatoid arthritis and significantly associated with low serum adalimumab trough levels and decreased clinical response [56, 59-61]. The relationship between pharmacokinetic data and efficacy is less clear for adalimumab than IFX with considerable variability and overlap in serum concentrations between patients with and without remission [57]. However, in an observational study evaluating the efficacy of adalimumab in 168 active CD patients who failed to respond to IFX, long-term clinical benefit was significantly associated with higher serum trough concentrations and absence of $\mathrm{ADAb}$ [56]. A recent study using adalimumab maintenance therapy in 40 adult patients with CD or UC showed a significant association of high trough levels of adalimumab with clinical remission and mucosal healing. Antiadalimumab antibodies were associated with low trough levels of adalimumab and lack of mucosal healing [58].

There is so far no data concerning trough levels and antidrug antibodies for adalimumab in children and in all patients for certolizumab and golimumab.

Serum trough levels measurement to detect subtherapeutic drug concentrations and identification of ADAb (therapeutic drug monitoring or TDM) are the most relevant and useful parameters for the monitoring of anti-TNF drugs to facilitate informed decision making in IBD patients with secondary loss of response to TNF antagonists. The clinical utility of the immunomonitoring was evaluated in a retrospective study conducted on 155 patients with IBD and loss of response to IFX [6]. They showed that measuring IFX and $\mathrm{ADAb}$ concentrations may impact treatment decision in $73 \%$. When ADAbs were detected, the switch to another anti-TNF molecule allowed a partial or complete response in $92 \%$ versus $17 \%$ for dose escalation whereas drug escalation was the most efficient strategy in patients with subtherapeutic
IFX concentration ( $86 \%$ versus $33 \%$ of partial or complete response, resp.). They concluded that increasing anti-TNF doses is ineffective in patients with $\mathrm{ADAb}$ but appropriate in case of subtherapeutic drug concentration and proposed an algorithm for optimization of therapeutic strategy in IBD patients with loss of response to IFX based on ADAb and trough drug measurement [6].

Interestingly, in a prospective study examining the course of $\mathrm{ADAb}$ formation and the clinical relevance of its assessment in the followup of patients with rheumatoid arthritis, Bartelds et al. showed that, among patients positive for antiadalimumab Abs, 67\% developed ADAbs during the first 28 weeks and almost one-third during the first month of treatment [62]. However and despite a poor clinical response, patients with ADAbs discontinued treatment only after 52 weeks of therapy indicating an important delay between ADAb appearance and treatment adjustment. Furthermore, early trough level measurement after induction might also have a prognostic value with IFX trough levels above $3.5 \mu \mathrm{g} / \mathrm{mL}$ at 14 weeks being associated with a sustained therapeutic response [63].

On the other hand, supratherapeutic anti-TNF trough levels might also be associated with paradoxical inflammatory side effects such as psoriasiform eczema or arthralgia [64]. In such patients, lowering doses could be beneficial in terms of not only safety but also decrease of the cost for the healthcare payer.

Altogether, these data plead for the clinical and economical utility of early therapeutic drug monitoring in the management of patients receiving TNF inhibitors. In case of a loss of response with low trough level without ADAb, an intensified therapy with the same drug should be recommended by increasing doses and/or decreasing intervals and eventually adding an immunosuppressant. When low trough level is related to the presence of ADAbs, therapy should be switched within the anti-TNF class and if necessary to a drug with another mode of action [63]. The addition of an immunomodulator might also be able to induce a decrease in ADAb level and to restore clinical response [65]. Of note, clinical response can occur despite the presence of ADAbs as described recently in a retrospective study [66]. Continued maintenance therapy with IFX induced ADAb disappearance in two-thirds of these patients after a median of 4 infusions suggesting that continued anti-TNF treatment could be considered in patients with clinical response and first $\mathrm{ADAb}$ detection. Indeed, recent studies investigating the kinetics of ATI formation confirmed that ADAb secretion may be transient and disappeared over time in almost onethird of patients $[67,68]$. Compared to nontransient ATI that appeared usually within the first 12 months of therapy, transient ATI was detected throughout the duration of IFX therapy [68]. Patients with sustained ATI were more likely to discontinue IFX treatment compared with patients with transient ATI [67].

In a very recent study using a decision analytic model that simulated 2 cohorts of patients with CD who become resistant to anti-TNF inhibitors, Velayos et al. compared the effectiveness of empiric dose escalation versus testingbased strategy over a 1-year time period [69]. Although both 
TABLE 1: Summary of the assays used in cited references for drug serum trough levels and ADAb measurement.

\begin{tabular}{lll}
\hline Assays & Company & References \\
\hline \multirow{2}{*}{ ELISA } & Prometheus Laboratories (San Diego, USA) & {$[3,4,6,66,70]$} \\
& Matriks Biotek Ltd. (Ankara, Turkey) & {$[45]$} \\
& Theradiag (Marne la Vallée, France) & {$[49,58,71]$} \\
& In house & {$[5,50,52,56,59,61,62,65,67,68,71]$} \\
\hline \multirow{2}{*}{ Radioimmune assay (RIA) } & Biomonitor A/S (Copenhagen, Denmark) & {$[46,66,70]$} \\
& In house & {$[51,59,60,62,71]$} \\
\hline Homogeneous mobility shift assay (HMSA) & Prometheus Laboratories (San Diego, USA) & {$[67]$} \\
\hline
\end{tabular}

strategies yielded similar rates of remission $(66 \%$ versus $63 \%$, resp.) and quality-adjusted life year (0.800 versus 0.801$)$, the testing-based strategy was less expensive than empiric dose escalation ( $\$ 31,870$ versus $\$ 34,266$, resp.). Similarly, Steenholdt et al. showed in a randomized controlled trial that a testing-based strategy using an algorithm designed to identify the mechanism leading to secondary loss of response to IFX is more cost effective than empiric dose escalation in patients with $\mathrm{CD}$ [70]. In the monitored arm, patients with low serum IFX and ATIs were switched to adalimumab, patients with low serum IFX without ATIs underwent dose intensification, and patients with high IFX trough levels with or without ATIs were switched to an out-of-class therapy or screened for an alternate cause of their symptoms. Compared to the current dose intensification strategy, individualized therapy substantially reduced average treatment costs per patient with similar clinical response rates.

Large prospective and randomized studies are still required to validate all these approaches in patients with IBD and clear dose toxicity/efficacy relationships have yet to be established for anti-TNF inhibitors.

Finally, we have to keep in mind that, in the absence of standardization, the numerous assays developed for serum trough levels and ADAb measurement (Table 1) exhibit variable performances that could explain discrepancies between studies and difficulties in establishing clear cutoff values. There are currently no defined gold standard assays for quantification of anti-TNF drugs and ADAbs. A recent study compared three in house or commercially available assays (ELISA, bridging ELISA, and RIA) developed for the analysis of IFX levels and ATIs [71]. There was a good correlation between IFX and ATI levels measured with all 3 tests. The sensitivity of the three assays to detect ATIs was comparable with a slight advantage for the RIA test which is less sensitive than ELISA to drug interference caused by the presence of IFX in the serum impeding the detection of low ATI concentrations. Nevertheless, discrepancies between the three assays were not rare and conclusions of the study were highly debated highlighting the high need for standardization $[72,73]$.

\section{Conclusion}

Since the advent of anti-TNF biologics more than a decade ago, they have demonstrated beneficial activity in induction and maintenance of clinical responses, mucosal healing, improvement in quality of life, reduction in surgeries and hospitalizations, and the treatment of extraintestinal manifestations of IBD. However, despite good overall initial effectiveness, a significant proportion of patients lose response over time mainly because of ADAb production and accelerated drug clearance. Although optimal treatment strategies remain controversial, therapeutic algorithms were proposed based on serum trough levels and ADAb monitoring in order to rationalize drug adjustment. For the future, a better understanding of the ambivalent protective and deleterious effects mediated by $\mathrm{TNF} \alpha$ and its receptors on immune and nonimmune cells during IBD might be crucial for the development of more efficient and safe biological inhibitors.

\section{Conflict of Interests}

The authors declare that they have no conflict of interests regarding the publication of this paper.

\section{References}

[1] S. Danese, J. F. Colombel, L. Peyrin-Biroulet, P. Rutgeerts, and W. Reinisch, "Review article: the role of anti-TNF in the management of ulcerative colitis-past, present and future," Alimentary Pharmacology \& Therapeutics, vol. 37, no. 9, pp. 855866, 2013.

[2] L. Peyrin-Biroulet and M. Lémann, "Review article: remission rates achievable by current therapies for inflammatory bowel disease," Alimentary Pharmacology and Therapeutics, vol. 33, no. 8, pp. 870-879, 2011.

[3] E. A. Maser, R. Villela, M. S. Silverberg, and G. R. Greenberg, "Association of trough serum infliximab to clinical outcome after scheduled maintenance treatment for Crohn's disease," Clinical Gastroenterology and Hepatology, vol. 4, no. 10, pp. 1248-1254, 2006.

[4] C. H. Seow, A. Newman, S. P. Irwin, A. H. Steinhart, M. S. Silverberg, and G. R. Greenberg, "Trough serum infliximab: a predictive factor of clinical outcome for infliximab treatment in acute ulcerative colitis," Gut, vol. 59, no. 1, pp. 49-54, 2010.

[5] F. Baert, M. Noman, S. Vermeire et al., "Influence of immunogenicity on the long-term efficacy of infliximab in Crohn's disease," The New England Journal of Medicine, vol. 348, no. 7, pp. 601-608, 2003.

[6] W. Afif, E. V. Loftus Jr., W. A. Faubion et al., "Clinical utility of measuring infliximab and human anti-chimeric antibody concentrations in patients with inflammatory bowel disease," The American Journal of Gastroenterology, vol. 105, no. 5, pp. 1133-1139, 2010. 
[7] I. Monteleone, F. Pallone, and G. Monteleone, "Th17-related cytokines: new players in the control of chronic intestinal inflammation," BMC Medicine, vol. 9, article 122, 2011.

[8] C. Mueller, "Tumour necrosis factor in mouse models of chronic intestinal inflammation," Immunology, vol. 105, no. 1, pp. 1-8, 2002.

[9] D. J. MacEwan, “TNF receptor subtype signalling: differences and cellular consequences," Cellular Signalling, vol. 14, no. 6, pp. 477-492, 2002.

[10] H. Wajant, K. Pfizenmaier, and P. Scheurich, "Tumor necrosis factor signaling," Cell Death and Differentiation, vol. 10, no. 1, pp. 45-65, 2003.

[11] R. M. Aspalter, M. M. Eibl, and H. M. Wolf, "Regulation of TCRmediated T cell activation by TNF-RII," Journal of Leukocyte Biology, vol. 74, no. 4, pp. 572-582, 2003.

[12] R. Dahlen, H. Strid, A. Lundgren et al., "Infliximab inhibits activation and effector functions of peripheral blood $\mathrm{T}$ cells in vitro from patients with clinically active ulcerative colitis," Scandinavian Journal of Immunology, vol. 78, no. 3, pp. 275-284, 2013.

[13] X. Chen, X. Wu, Q. Zhou, O. M. Howard, M. G. Netea, and J. J. Oppenheim, "TNFR2 is critical for the stabilization of the CD4+Foxp3+ regulatory T. cell phenotype in the inflammatory environment," Journal of Immunology, vol. 190, no. 3, pp. 10761084, 2013.

[14] X. Chen and J. J. Oppenheim, "Contrasting effects of TNF and anti-TNF on the activation of effector T cells and regulatory $\mathrm{T}$ cells in autoimmunity," FEBS Letters, vol. 585, no. 23, pp. 36113618, 2011.

[15] K. Wang, G. Han, Y. Dou et al., "Opposite role of tumor necrosis factor receptors in dextran sulfate sodium-induced colitis in mice," PLoS ONE, vol. 7, no. 12, Article ID e52924, 2012.

[16] S. Danese, J.-F. Colombel, W. Reinisch, and P. J. Rutgeerts, "Review article: infliximab for Crohn's disease treatmentshifting therapeutic strategies after 10 years of clinical experience," Alimentary Pharmacology and Therapeutics, vol. 33, no. 8, pp. 857-869, 2011.

[17] S. B. Hanauer, A. A. Kornbluth, J. Messick, D. T. Rubin, W. J. Sandborn, and B. E. Sands, "Clinical scenarios in IBD: optimizing the use of conventional and biologic agents," Inflammatory Bowel Diseases, vol. 16, no. 1, pp. S1-S11, 2010.

[18] T. Billiet, P. Rutgeerts, M. Ferrante, G. Van Assche, and S. Vermeire, "Targeting TNF-alpha for the treatment of inflammatory bowel disease," Expert Opinion on Biological Therapy, vol. 14, no. 1, pp. 75-101, 2014.

[19] S. R. Targan, S. B. Hanauer, S. J. H. Van Deventer et al., "A shortterm study of chimeric monoclonal antibody cA2 to tumor necrosis factor $\alpha$ for Crohn's Disease," The New England Journal of Medicine, vol. 337, no. 15, pp. 1029-35, 1997.

[20] A. Dignass, G. Van Assche, J. O. Lindsay et al., "The second European evidence-based consensus on the diagnosis and management of Crohn's disease: current management," Journal of Crohn's and Colitis, vol. 4, no. 1, pp. 28-62, 2010.

[21] A. Dignass, J. O. Lindsay, A. Sturm et al., "Second European evidence-based consensus on the diagnosis and management of ulcerative colitis part 2: current management," Journal of Crohn's and Colitis, vol. 6, no. 10, pp. 991-1030, 2012.

[22] J. S. Hyams, T. Lerer, A. Griffiths et al., "Outcome following infliximab therapy in children with ulcerative colitis," The American Journal of Gastroenterology, vol. 105, no. 6, pp. 14301436, 2010.
[23] J. Hyams, W. Crandall, S. Kugathasan et al., "Induction and maintenance infliximab therapy for the treatment of moderateto-severe Crohn's disease in children," Gastroenterology, vol.132, no. 3, pp. 863-873, 2007.

[24] R. K. Russell, M. L. Wilson, S. Loganathan et al., "A british society of paediatric gastroenterology, hepatology and nutrition survey of the effectiveness and safety of Adalimumab in children with inflammatory bowel disease," Alimentary Pharmacology and Therapeutics, vol. 33, no. 8, pp. 946-953, 2011.

[25] S. Mian and H. Baron, "Adalimumab, a novel anti-tumor necrosis factor- $\alpha$ antibody in a child with refractory Crohn's disease," Journal of Pediatric Gastroenterology and Nutrition, vol. 41, no. 3, pp. 357-359, 2005.

[26] J. F. Colombel, W. J. Sandborn, W. Reinisch et al., "Infliximab, azathioprine, or combination therapy for Crohn's disease," The New England Journal of Medicine, vol. 362, no. 15, pp. 1383-1395, 2010.

[27] B. E. Sands, M. A. Blank, K. Patel, and S. J. Van Deventer, "Longterm treatment of rectovaginal fistulas in Crohn's disease: response to infliximab in the ACCENT II study," Clinical Gastroenterology and Hepatology, vol. 2, no. 10, pp. 912-920, 2004.

[28] J.-F. Colombel, W. J. Sandborn, P. Rutgeerts et al., "Adalimumab for maintenance of clinical response and remission inpatients with Crohn's disease: the CHARM Trial," Gastroenterology, vol. 132, no. 1, pp. 52-65, 2007.

[29] S. Schreiber, P. Rutgeerts, R. N. Fedorak et al., "A randomized, placebo-controlled trial of certolizumab pegol (CDP870) for treatment of Crohn's disease," Gastroenterology, vol. 129, pp. 807-818, 2005.

[30] W. J. Sandborn, B. G. Feagan, C. Marano et al., "Subcutaneous golimumab maintains clinical response in patients with moderate-to-severe ulcerative colitis," Gastroenterology, vol. 146, no. 1, pp. 96.e1-109.e1, 2014.

[31] W. J. Sandborn, B. G. Feagan, C. Marano et al., "Subcutaneous golimumab induces clinical response and remission in patients with moderate-to-severe ulcerative colitis," Gastroenterology, vol. 146, no. 1, pp. 85-95, 2014.

[32] F. Schnitzler, H. Fidder, M. Ferrante et al., "Long-term outcome of treatment with infliximab in 614 patients with Crohn's disease: results from a single-centre cohort," Gut, vol. 58, no. 4, pp. 492-500, 2009.

[33] H. Yanai and S. B. Hanauer, "Assessing response and loss of response to biological therapies in IBD," The American Journal of Gastroenterology, vol. 106, no. 4, pp. 685-698, 2011.

[34] G. Van Assche, C. Magdelaine-Beuzelin, G. D'Haens et al., "Withdrawal of immunosuppression in Crohn's disease treated with scheduled infliximab maintenance: a randomized trial," Gastroenterology, vol. 134, no. 7, pp. 1861-1868, 2008.

[35] V. Billioud, W. J. Sandborn, and L. Peyrin-Biroulet, "Loss of response and need for adalimumab dose intensification in Crohn's disease: a systematic review," The American Journal of Gastroenterology, vol. 106, no. 4, pp. 674-684, 2011.

[36] W. J. Sandborn, J.-F. Colombel, S. Schreiber et al., "Dosage adjustment during long-term adalimumab treatment for Crohn's disease: clinical efficacy and pharmacoeconomics," Inflammatory Bowel Diseases, vol. 17, no. 1, pp. 141-151, 2011.

[37] L. Peyrin-Biroulet, P. Deltenre, N. de Suray, J. Branche, W. J. Sandborn, and J.-F. Colombel, "Efficacy and safety of tumor necrosis factor antagonists in Crohn's disease: meta-analysis of placebo-controlled trials," Clinical Gastroenterology and Нераtology, vol. 6, no. 6, pp. 644-653, 2008. 
[38] A. A. Fasanmade, O. J. Adedokun, M. Blank, H. Zhou, and H. M. Davis, "Pharmacokinetic properties of infliximab in children and adults with Crohn's disease: a retrospective analysis of data from 2 Phase III clinical trials," Clinical Therapeutics, vol. 33, no. 7, pp. 946-964, 2011.

[39] A. A. Fasanmade, O. J. Adedokun, J. Ford et al., "Population pharmacokinetic analysis of infliximab in patients with ulcerative colitis," European Journal of Clinical Pharmacology, vol. 65, no. 12, pp. 1211-1228, 2009.

[40] I. Ordás, D. R. Mould, B. G. Feagan, and W. J. Sandborn, “AntiTNF monoclonal antibodies in inflammatory bowel disease: pharmacokinetics-based dosing paradigms," Clinical Pharmacology and Therapeutics, vol. 91, no. 4, pp. 635-646, 2012.

[41] K. S. Nanda, A. S. Cheifetz, and A. C. Moss, "Impact of antibodies to infliximab on clinical outcomes and serum infliximab levels in patients with inflammatory bowel disease (IBD): a meta-analysis," The American Journal of Gastroenterology, vol. 108, no. 1, pp. 40-47, 2013.

[42] Z. Xu, K. Seitz, A. Fasanmade et al., "Population pharmacokinetics of infliximab in patients with ankylosing spondylitis," Journal of Clinical Pharmacology, vol. 48, no. 6, pp. 681-695, 2008.

[43] A. C. Moss, V. Brinks, and J. F. Carpenter, "Review article: immunogenicity of anti-TNF biologics in IBD—the role of patient, product and prescriber factors," Alimentary Pharmacology \& Therapeutics, vol. 38, no. 10, pp. 1188-1197, 2013.

[44] S. Vermeire, M. Noman, G. Van Assche, F. Baert, G. D’Haens, and P. Rutgeerts, "Effectiveness of concomitant immunosuppressive therapy in suppressing the formation of antibodies to infliximab in Crohn's disease," Gut, vol. 56, no. 9, pp. 1226-1231, 2007.

[45] M. Bortlik, D. Duricova, K. Malickova et al., "Infliximab trough levels may predict sustained response to infliximab in patients with Crohn's disease," Journal of Crohn's and Colitis, vol. 7, no. 9, pp. 736-743, 2012.

[46] C. Steenholdt, K. Bendtzen, J. Brynskov, O. Ø. Thomsen, and M. A. Ainsworth, "Cut-off levels and diagnostic accuracy of infliximab trough levels and anti-infliximab antibodies in Crohn's disease," Scandinavian Journal of Gastroenterology, vol. 46, no. 3, pp. 310-318, 2011.

[47] T. Hibi, A. Sakuraba, M. Watanabe et al., "Retrieval of serum infliximab level by shortening the maintenance infusion interval is correlated with clinical efficacy in Crohn's disease," Inflammatory Bowel Diseases, vol. 18, no. 8, pp. 1480-1487, 2012.

[48] O. J. Adedokun, Z. Xu, L. Padgett et al., "Pharmacokinetics of infliximab in children with moderate-to-severe ulcerative colitis: results from a randomized, multicenter, open-label, phase 3 study," Inflammatory Bowel Diseases, vol. 19, no. 13, pp. 2753-2762, 2013.

[49] S. Paul, E. Del Tedesco, H. Marotte et al., "Therapeutic drug monitoring of infliximab and mucosal healing in inflammatory bowel disease: a prospective study," Inflammatory Bowel Diseases, vol. 19, no. 12, pp. 2568-2576, 2013.

[50] S. Ben-Horin, M. Yavzori, L. Katz et al., “The immunogenic part of infliximab is the $\mathrm{F}\left(\mathrm{ab}^{\prime}\right) 2$, but measuring antibodies to the intact infliximab molecule is more clinically useful," Gut, vol. 60, no. 1, pp. 41-48, 2011.

[51] M. A. Ainsworth, K. Bendtzen, and J. Brynskov, “Tumor necrosis factor-alpha binding capacity and anti-infliximab antibodies measured by fluid-phase radioimmunoassays as predictors of clinical efficacy of infliximab in Crohn's disease," The American Journal of Gastroenterology, vol. 103, no. 4, pp. 944-948, 2008.
[52] H. Imaeda, S. Bamba, K. Takahashi et al., "Relationship between serum infliximab trough levels and endoscopic activities in patients with Crohn's disease under scheduled maintenancetreatment," Journal of Gastroenterology. In press.

[53] B. Pariente, G. P. De Chambrun, R. Krysiek et al., “Trough levels and antibodies to infliximab may not predict response to intensification of infliximab therapy in patients with inflammatory bowel disease," Inflammatory Bowel Diseases, vol. 18, no. 7, pp. 1199-1206, 2012.

[54] A. Cassinotti and S. Travis, "Incidence and clinical significance of immunogenicity to infliximab in Crohn's disease: a critical systematic review," Inflammatory Bowel Diseases, vol. 15, no. 8, pp. 1264-1275, 2009.

[55] S. B. Hanauer, C. L. Wagner, M. Bala et al., "Incidence and importance of antibody responses to infliximab after maintenance or episodic treatment in Crohn's disease," Clinical Gastroenterology and Hepatology, vol. 2, no. 7, pp. 542-553, 2004.

[56] K. Karmiris, G. Paintaud, M. Noman et al., "Influence of trough serum levels and immunogenicity on long-term outcome of adalimumab therapy in Crohn's disease," Gastroenterology, vol. 137, no. 5, pp. 1628-1640, 2009.

[57] Y. L. Chiu, D. T. Rubin, S. Vermeire et al., "Serum adalimumab concentration and clinical remission in patients with Crohn's disease," Inflammatory Bowel Diseases, vol. 19, no. 6, pp. 11121122, 2013.

[58] X. Roblin, H. Marotte, M. Rinaudo et al., "Association between pharmacokinetics of adalimumab and mucosal healing in patients with inflammatory bowel diseases," Clinical Gastroenterology and Hepatology, vol. 12, no. 1, pp. 80.e2-84.e2, 2014.

[59] G. M. Bartelds, C. A. Wijbrandts, M. T. Nurmohamed et al., "Clinical response to adalimumab: relationship to antiadalimumab antibodies and serum adalimumab concentrations in rheumatoid arthritis," Annals of the Rheumatic Diseases, vol. 66, no. 7, pp. 921-926, 2007.

[60] R. L. West, Z. Zelinkova, G. J. Wolbink, E. J. Kuipers, P. C. F. Stokkers, and C. J. Van Der Woude, "Immunogenicity negatively influences the outcome of adalimumab treatment in Crohn's disease," Alimentary Pharmacology and Therapeutics, vol. 28, no. 9, pp. 1122-1126, 2008.

[61] H. Imaeda, K. Takahashi, T. Fujimoto et al., "Clinical utility of newly developed immunoassays for serum concentrations of adalimumab and anti-adalimumab antibodies in patients with Crohn's disease," Journal of Gastroenterology, vol. 49, no. 1, pp. 100-109, 2014.

[62] G. M. Bartelds, C. L. M. Krieckaert, M. T. Nurmohamed et al., "Development of antidrug antibodies against adalimumab and association with disease activity and treatment failure during longterm follow-up," Journal of the American Medical Association, vol. 305, no. 14, pp. 1460-1468, 2011.

[63] S. Vermeire and A. Gils, "Value of drug level testing and antibody assays in optimising biological therapy," Frontline Gastroenterology, vol. 4, no. 1, pp. 41-43, 2013.

[64] I. Cleynen and S. Vermeire, "Paradoxical inflammation induced by anti-TNF agents in patients with IBD," Nature Reviews Gastroenterology \& Hepatology, vol. 9, no. 9, pp. 496-503, 2012.

[65] S. Ben-Horin, M. Waterman, U. Kopylov et al., "Addition of an immunomodulator to infliximab therapy eliminates antidrug antibodies in serum and restores clinical response of patients with inflammatory bowel disease," Clinical Gastroenterology and Hepatology, vol. 11, no. 4, pp. 444-447, 2013. 
[66] C. Steenholdt, M. Al-khalaf, J. Brynskov, K. Bendtzen, O. Thomsen, and M. A. Ainsworth, "Clinical implications of variations in anti-infliximab antibody levels in patients with inflammatory bowel disease," Inflammatory Bowel Diseases, vol. 18, no. 12, pp. 2209-2217, 2012.

[67] N. Vande Casteele, A. Gils, S. Singh et al., "Antibody response to infliximab and its impact on pharmacokinetics can be transient," The American Journal of Gastroenterology, vol. 108, no. 6, pp. 962-971, 2013.

[68] B. Ungar, Y. Chowers, M. Yavzori et al., "The temporal evolution of antidrug antibodies in patients with inflammatory bowel disease treated with infliximab," Gut, 2013.

[69] F. S. Velayos, J. G. Kahn, W. J. Sandborn, and B. G. Feagan, "A test-based strategy is more cost effective than empiric dose escalation for patients with Crohn's Disease who lose responsiveness to infliximab," Clinical Gastroenterology and Hepatology, vol. 11, no. 6, pp. 654-666, 2013.

[70] C. Steenholdt, J. Brynskov, O. O. Thomsen et al., "Individualised therapy is more cost-effective than dose intensification in patients with Crohn's disease who lose response to anti-TNF treatment: a randomised, controlled trial," Gut, 2013.

[71] N. Vande Casteele, D. J. Buurman, M. G. Sturkenboom et al., "Detection of infliximab levels and anti-infliximab antibodies: a comparison of three different assays," Alimentary Pharmacology \& Therapeutics, vol. 36, no. 8, pp. 765-771, 2012.

[72] D. J. Buurman, N. Vande Casteele, M. G. Sturkenboom et al., "Letter: detection of infliximab levels and anti-infliximab antibodies-comparison of three different assays, authors' reply," Alimentary Pharmacology \& Therapeutics, vol. 37, no. 2, p. 282, 2013.

[73] E. Parussini, "Letter: detection of infliximab levels and antiinfliximab antibodies-comparison of three different assays," Alimentary Pharmacology \& Therapeutics, vol. 37, no. 2, p. 281, 2013. 


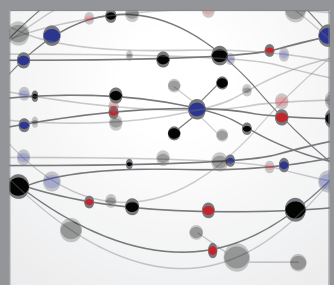

The Scientific World Journal
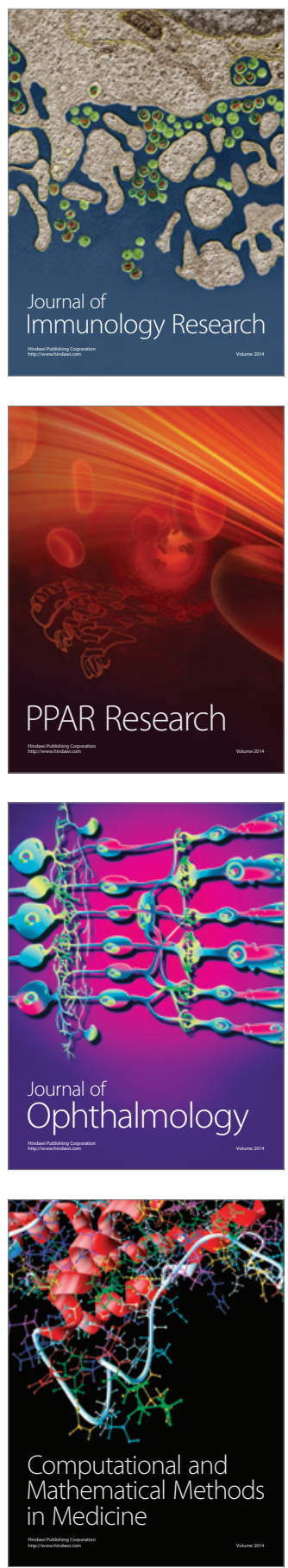

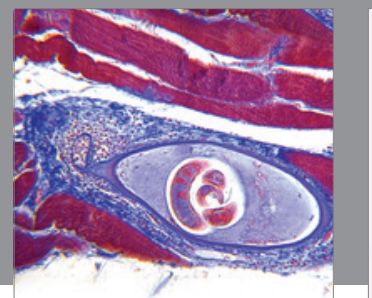

Gastroenterology

Research and Practice
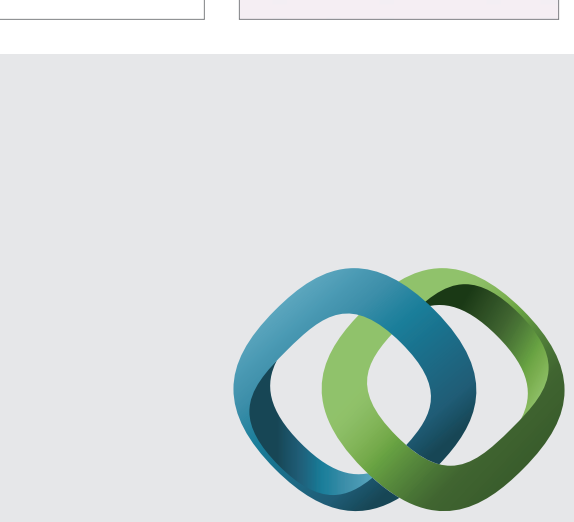

\section{Hindawi}

Submit your manuscripts at

http://www.hindawi.com
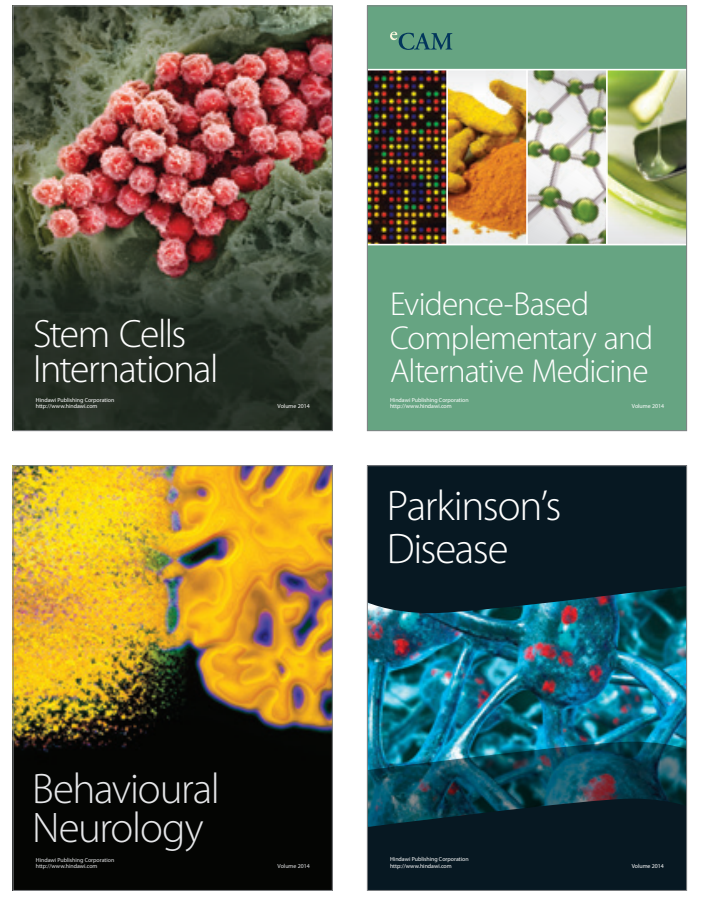
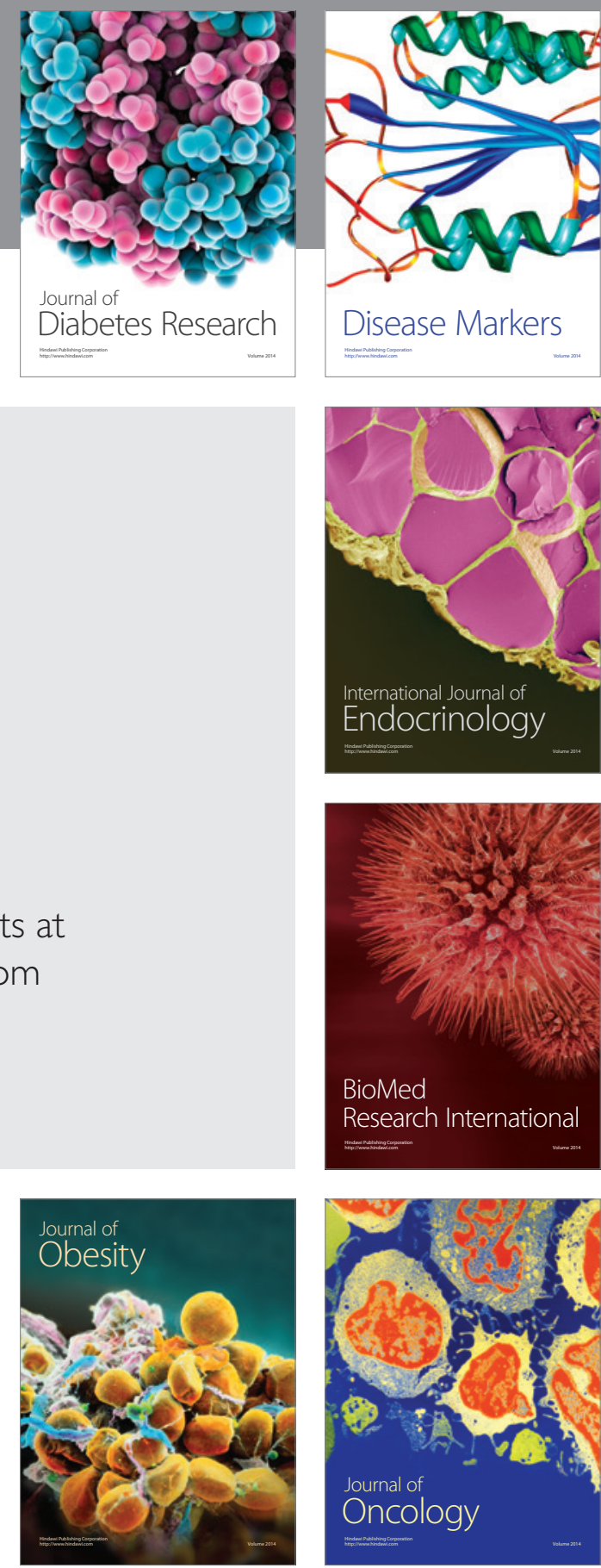

Disease Markers
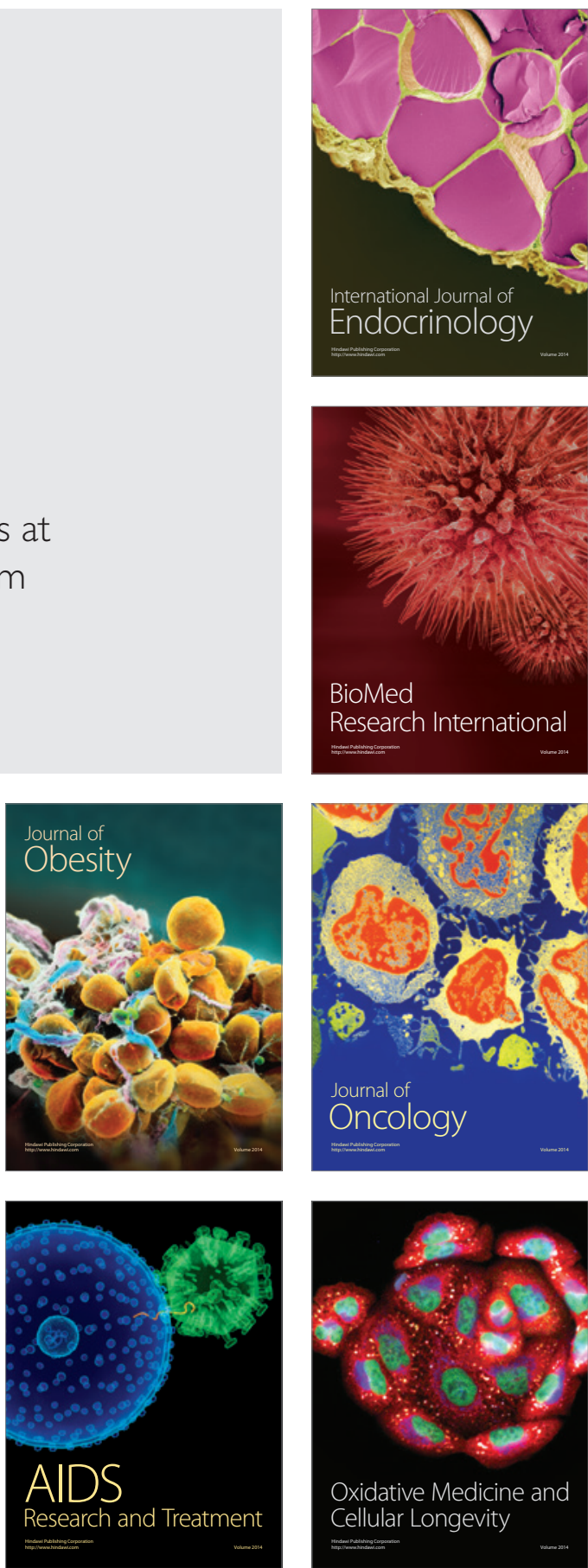